DOI: $10.21767 / 2572-5548.100013$

\title{
Emphysema's Holy Grail, The Quest for Endobronchial Lung Volume Reduction
}

\author{
James D Maloney and Ryan A Macke
}

Department of Surgery, Cardiothoracic Surgery, University of Wisconsin, USA

Corresponding author: Maloney JD, Associate Professor of Surgery, Section Chief-Thoracic Surgery, University of Wisconsin, Department of Surgery, Cardiothoracic Surgery, 600 Highland Ave, H4/318, Madison, WI 53792-3236, USA, Tel: 608-263-5215; Fax: 608-265-6450; E-mail: maloney@surgery.wisc.edu

Rec date: July 27, 2016; Acc date: July 30, 2016; Pub date: August 4, 2016

Copyright: (C) 2016 Maloney JD, et al. This is an open-access article distributed under the terms of the Creative Commons Attribution License, which permits unrestricted use, distribution, and reproduction in any medium, provided the original author and source are credited.

Citation: Maloney JD, Macke RA (2016) Emphysema's Holy Grail, The Quest for Endobronchial Lung Volume Reduction. Chron Obstruct Pulmon Dis 1: 13.

\section{Letter to Editor,}

Bronchoscopic lung volume reduction has become the Holy Grail of pulmonologists who treat COPD in both the United States and abroad. In some ways this if fitting as "chronic lower respiratory disease" is now the fourth leading cause of death in the US [1]. In addition, COPD severely impacts quality of life and is a significant cost burden [2]. It is now more than five years ago Drs Ernst and Anantham published their review of Bronchoscopic lung volume reduction in Clinical Chest Medicine [3]. At that time endobronchial valve, airway bypass stent and biologic LVR trials had occurred though none proved to be of sufficient clinical value to warrant inclusion in standard COPD treatment algorithms. The most recent iteration of this quest is documented in JAMA regarding the RENEW endobronchial coil study. This technology was exciting as traction providing coils would not be subject to the crossventilation which has been implicated in the limited effect of endobronchial valves [4]. Unfortunately, Dr. Sciurba and colleagues found that the benefits derived by the study patients with the treatment was of "uncertain clinical importance, with a higher likelihood of major complications" [5]. Like all thoracic surgeons who treat COPD, we sympathize with the authors as major complications are something with which we are all too familiar. My colleagues and I have reported the short term outcomes of Lung Volume Reduction Surgery (LVRS) from Society of Thoracic Surgery database review from 2003-2011, confirming that surgical intervention has risk of morbidity and mortality [6]. However, along with the risk of the procedure comes a documented significant benefit, demonstrated in exercise capacity, subjective dyspnea and FEV1 [7,8]. Most importantly, Dr. Naunheim and colleagues found that in the upper lobe predominant, low exercise capacity sub group 5-year survival was improved over best medical management [8]. Though this data is readily available and relevant with the increasing numbers of severe emphysema patients, overall limited organ availability, and shift in lung allocation toward the fibrotic lung population, LVRS is still met with skepticism in the pulmonology community. As a group we must decide if we believe that reducing the volume of hyper-expanded COPD patients is effective in treating their symptoms and improving their quality, and perhaps quantity of life. The data certainly suggests this is the case. Despite this the volume of LVRS in the United States is surprisingly low relative to the prevalence of COPD. Education and discussion is needed between the thoracic surgical and medical community so that patients are given the opportunity to investigate their treatment options. While continuing the quest in a systematic and responsible way for the grail of an endoscopic approach, surgical LVRS remains an option in appropriately chosen patients at high volume centers with multidisciplinary programs.

\section{References}

1. Murphy SL, Kochanek KD, Xu J, Arias E (2015) Mortality in the United States. 2014 NCHS Data Brief No 229.

2. American Lung Association (2010) Trends in COPD (emphysema and chronic bronchitis): morbidity and mortality.

3. Ernst A, Anantham D (2010) Endoscopic management of emphysema. Clin Chest Med 31: 117-126.

4. Gompelmann D, Eberhardt R, Michaud G, Ernst A, Herth $F$ (2010) Predicting Atelectasis by assessment of collateral ventilation prior to endobronchial lung volume reduction; A feasibility study. Respiration 80: 419-425.

5. Sciurba FC, Criner GJ, Strange C, Shah PL, Michaud G, et al. (2016) Effect of endobronchial coils vs usual care on exercise tolerance in patients with severe emphysema: The RENEW Randomized Clinical Trial. JAMA 315: 2178-2189.

6. Decker MM, Leversen GE, Abi Jouade W, Maloney JD (2014) Lung volume reduction surgerysince the Nation Emphysema Treatment Trial: Study of the Society of Thoracic Surgeons database. J Thorac Cardiovasc Surg 148: 2651-2658.

7. Fishman A, Martinez F, Naunheim K, Piantadosi S, Wise R, et al. (2003) A randomized trial comparing lung-volume-reduction surgery with medical therapy for sever emphysema. N Engl J Med 348: 2059-2073.

8. Naunheim KS, Wood DE, Mohsenifar Z, Sternberg AL, Criner GJ, et al. (2006) Long-term follow-up of patients receiving lungvolume-reduction surgery versus medical therapy for severe emphysema by the National Emphysema Treatment Trial Research Group. Ann Thorac Surg 82: 431-443. 